\title{
Polymer Foam Core Aluminum Sandwich Lightweight Car Hood for Pedestrian Protection
}

\author{
Y. $\mathrm{CAN}^{a, *}, \mathrm{M}$. YAZICI ${ }^{b}$ AND H. GÜÇLÜ̈ \\ ${ }^{a}$ R\&D Center, Oyak-Renault, Bursa, Turkey \\ ${ }^{b}$ Uludağ University, Engineering Faculty, Automotive Engineering Department, Nilüfer, Bursa, Turkey \\ In this study, various sandwich structures were designed for application in car hoods to reduce the pedestrian \\ head injuries. In the sandwich panels, the face sheets were made of thin aluminum and steel plates, and the core \\ materials were chosen to be of polymer foams. Polymer foams have high energy absorbing performance under \\ impact loading. They can be unflammable and resistive to high-temperatures, depending on the base polymer. \\ The main goal of the presented study is to develop a sandwich structure for car hood to reduce fatality in the \\ pedestrian-car accidents by decreasing the value of head injury criterion. Sandwich panel face sheet, polymer foam \\ core thickness, and two different face sheet material were studied as research parameters using the finite element \\ analysis. The pedestrian headform was modeled according to EEVC/WG17 regulations and used in the finite \\ element simulations. The lightest hood and the minimum head injury criterion value have been achieved using the \\ thinner steel front face and the thicker foam core.
}

DOI: 10.12693/APhysPolA.134.231

PACS/topics: pedestrian protection, sandwich panel, light-weighting, finite element method

\section{Introduction}

The pedestrian-vehicle traffic accidents are one of the largest health problems in the World. The car manufacturers are paying attention to this subject and trying to reduce the fatal results by developing active or passive safety solutions. One of the passive safety systems is based on using energy absorbing materials in the most car body elements which can contact with pedestrians. These components absorb more energy during the pedestrian-vehicle impacts and cause less injury to the pedestrian bodies. In the collision one of the most critical parts of the pedestrian body is the head [1].

The main function of the car hood is to cover the engine compartment. It also helps to manage the impact energy during a vehicle-pedestrian crash. European Enhanced Vehicle Safety Committee (EEVC) working group 17 has developed pedestrian safety verification tests. Impact of an adult headform in the specified hood areas with a $65^{\circ}$ angle at $40 \mathrm{~km} / \mathrm{h}$ velocity is one of the protection rating tests [2]. The level of injuries in a vehicle-pedestrian crash depends on various factors, such as energy absorption capability of the car body, hood shape, bumper geometry, deformation limits of the used materials, areas of contact with the pedestrian, position, size, and age of the pedestrian $[3,4]$.

Overall, vehicle components have induced more than $85 \%$ of pedestrian injuries, highlighting the importance of designing pedestrian-friendly vehicles [4].

In the presented study two polymer foam core lightweight sandwich panels were investigated, regarding pedestrian protection and vehicle mass reduction,

*corresponding author; e-mail: yucel.can@renault.com using FE simulations. All FE simulations were performed in Abaqus ${ }^{\circledR} 6.14$ software. The HIC, hood deflections and hood masses calculated using the FE method were compared with corresponding parameters of original steel hood.

\section{Materials and methods}

\subsection{Problem definition and FE modeling}

An original steel car hood is made of steel and consists of two parts, the outer car hood (Fig. 1a) and the inner car hood (Fig. 1b), joined by edge hemming. In the FE model, this joining is described by tie contacts. This assembly model was used in analysis as the reference simulation to compare the developed sandwich panels.

Two types of the polymer foam core sandwich panels were analyzed. Both have the same foam core. Face sheet was selected to be of aluminum and steel with different thicknesses. The adult headform was used as the impactor. The FE model of the original hood assembly is shown in Fig. 1c with the adult headform model. Fixed boundary conditions on all sides were applied in the car hood models (Fig. 1d). In the original car hood FE mesh model, 160653 nodes and 159519 elements (C3D8R, R3D3, R3D4, S3R, S4R) were used.

The sandwiched car hoods were modeled by two similar layers of face sheet and polymer foam core (Fig. 2a). The face sheet geometry was obtained from the original car hood outer surface. Thicknesses of both the aluminum and the steel face sheets was set to $0.3 \mathrm{~mm}$. The foam core surface geometry was the same as that of the face sheets. Three different foam core thicknesses of $5 \mathrm{~mm}, 15 \mathrm{~mm}$, and $25 \mathrm{~mm}$ were studied. In case 2 and case 3 the same FE models were used by changing face sheet materials. Figure $2 \mathrm{~b}$ shows the meshed car hood sandwich structure. 

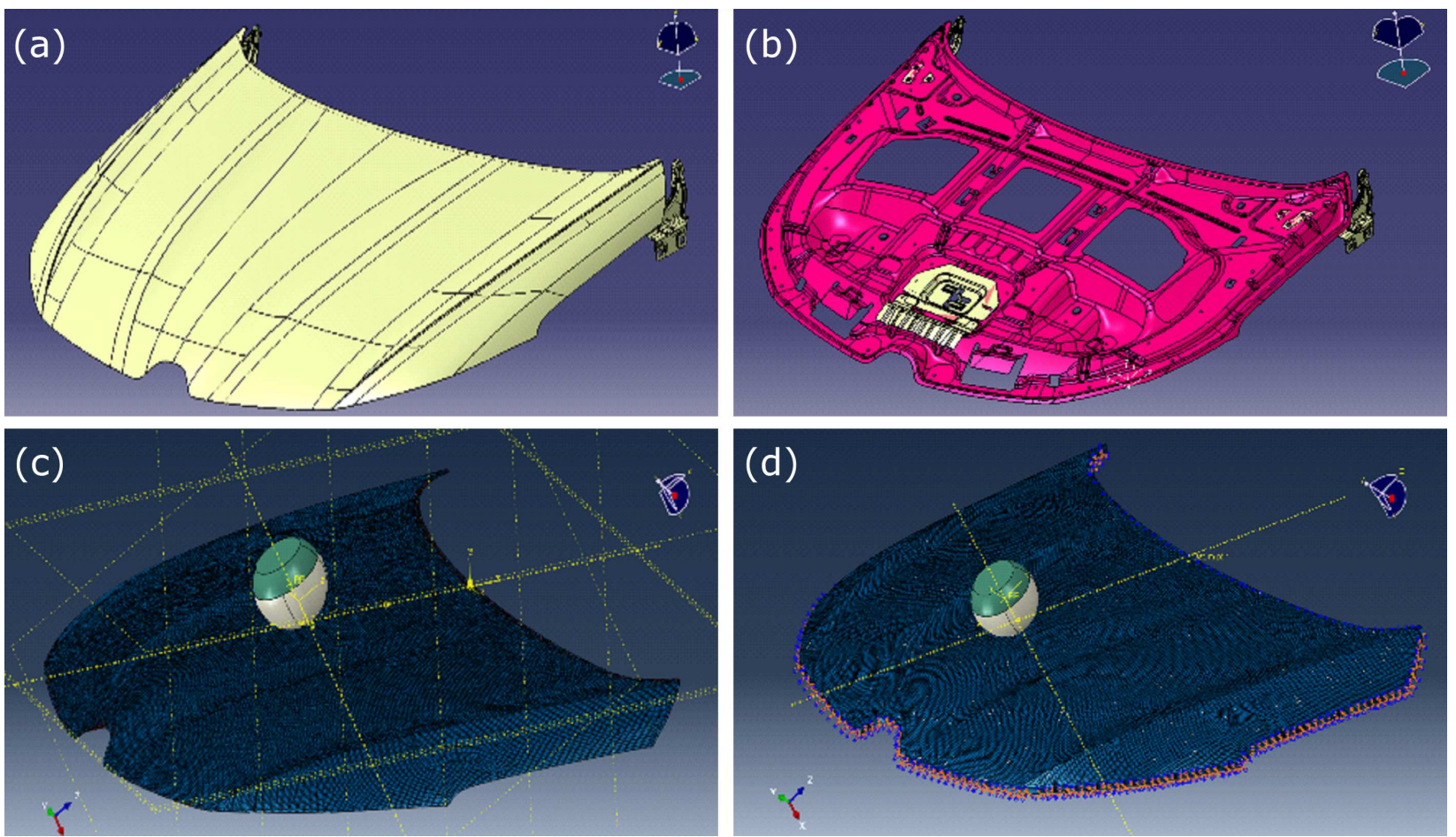

Fig: 1. Original steel car hood model (case 1). (a) The outer car hood CAD model, (b) the inner car hood CAD model, (c) FE model, (d) boundary conditions
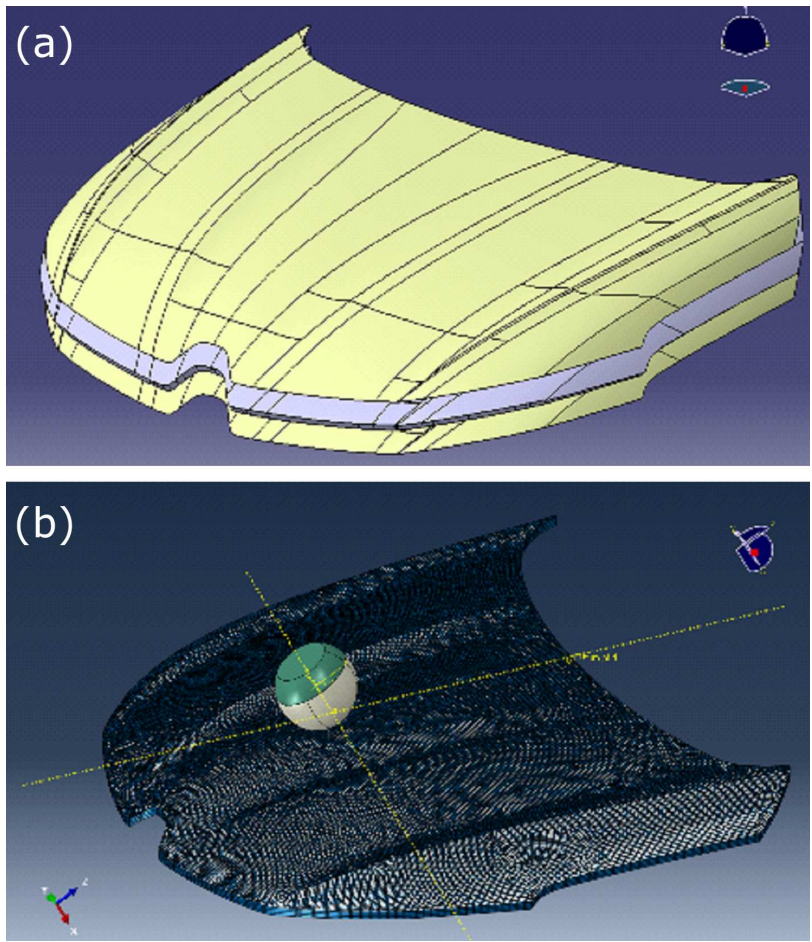

Fig. 2. (a) Sandwich car hood CAD model, (b) FE model of the sandwich car hood with adult headform.

In the sandwiched hoods, the total number of 378276 nodes and 316406 elements were generated with various element types.
In foam cores the number of nodes and elements changed depending on the thickness. In $5 \mathrm{~mm}$ foam there were 122048 nodes and 61277 elements (C3D8R and C3D6), in $15 \mathrm{~mm}$ foam there were 244096 nodes and 183831 elements, and in $25 \mathrm{~mm}$ foam there were 366144 nodes and 306385 elements. The meshes were optimized according to mesh size. All meshes in the FE models were verified by shape metrics and size metrics.

An adult head form was modeled for the simulations. Figure 3a shows the assembly model of the adult head form. Figure 3b shows the mass center of the assembled system for the acceleration measurements. Figure 3c shows rigid beam elements to transmit surface impact loads to acceleration measurement center. Figure 3d shows in addition the FE meshed adult headform geometry. This adult head model was used for pedestrian safety testing of the proposed sandwich car hood panels.

The employed adult headform impactor had a total weight of $4.8 \mathrm{~kg}$. It was composed of an aluminum sphere core and a thick $(13.9 \pm 0.5 \mathrm{~mm})$ vinyl skin cover. The vinyl skin cover was modeled as a viscoelastic material and aluminum core was modeled using a rigid material model. Adult headform was impacting the hood top surface with the speed of $11.1 \mathrm{~m} / \mathrm{s}$ according to EEVC regulations under an angle of 65 degrees from the ground plane.

The thick vinyl skin FE-model was generated using solid elements (type: C3D8R) connected to the aluminum core using a kinematic coupling element between the base of the skin and the reference node of the rigid body [5]. 

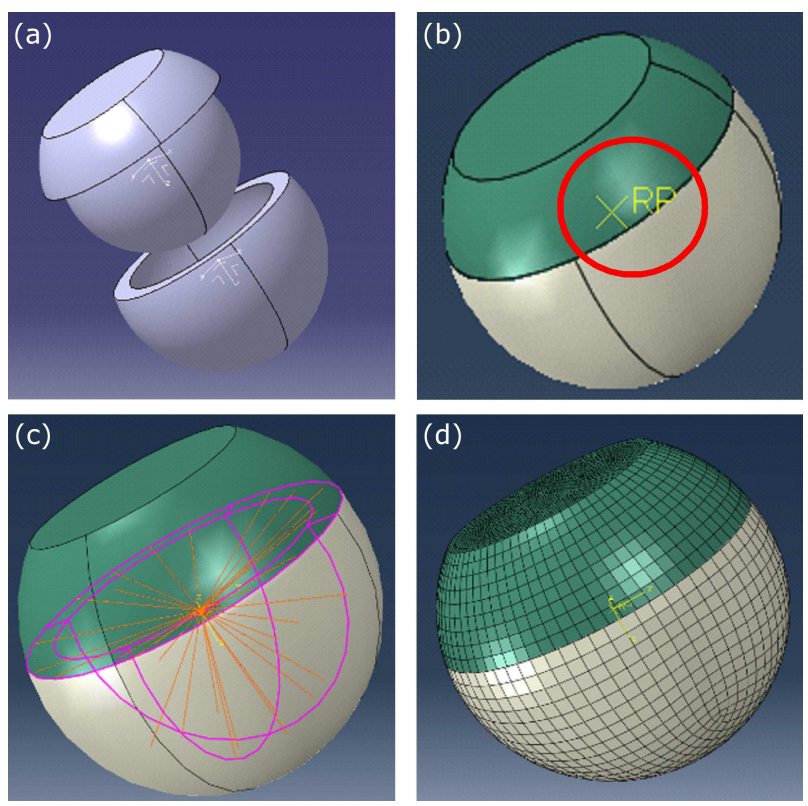

Fig. 3. Adult head impactor FE simulation model. (a) CAD model, (b) reference point, (c) kinematic coupling between the skin and the reference node, (d) FE mesh.

\subsection{Materials and model of materials}

The following materials were used in FEA analyses in the three investigated cases. The alloy quality low carbon steel and Al-2024-T3 type aluminum sheets were used for the hood structure. The material properties used in the simulations are presented in Table I. Sandwich hoods were constructed by using these face sheets and the polyurethane foam core. The polyurethane foam material parameters are given in Table II.

TABLE I

Properties of materials used for sandwich panel face sheets and for original car hoods.

\begin{tabular}{l|c|c|c|c|c}
\hline \hline Material & $\begin{array}{c}\text { Density } \\
{\left[\mathrm{kg} / \mathrm{m}^{3}\right]}\end{array}$ & $\begin{array}{c}\text { Young } \\
\text { modulus } \\
{[\mathrm{MPa}]}\end{array}$ & $\begin{array}{c}\text { Poisson } \\
\text { ratio }\end{array}$ & $\begin{array}{c}\text { Tensile } \\
\text { strength } \\
{[\mathrm{MPa}]}\end{array}$ & $\begin{array}{c}\text { Elongation } \\
\text { at break } \\
{[\%]}\end{array}$ \\
\hline low carbon steel & 7800 & 200000 & 0.30 & 360 & 35 \\
AL-2024-T3[6] & 2700 & 70000 & 0.33 & 483 & 18
\end{tabular}

TABLE II

Polyurethane foam Ogden-Hill parameters [7].

\begin{tabular}{c|c|c|c}
\hline \hline$N$ & $\mu[\mathrm{MPa}]$ & $\alpha$ & $\beta$ \\
\hline 1 & 12740.4 & 7.2810 & 0 \\
2 & 2.7459 & -5.7311 & 0
\end{tabular}

The sandwich foam core material is described in the Abaqus FEA software using OGDEN-HILL hyperfoam approach, as shown in Eq. (1). In this material model the hyperfoam is represented by a strain energy function. To completely characterize the strain energy function, it is the best to obtain data from several experiments involving different kinds of deformation over the range of strains of interest in an actual application and to use all of these data to determine the parameters [8]. Ogden-Hill hyperelastic foam model was used in the simulations.

$$
U=
$$

$$
\sum_{i=1}^{N} \frac{2 \mu_{i}}{\alpha_{i}^{2}}\left[\hat{\lambda}_{1}^{\alpha_{i}}+\hat{\lambda}_{2}^{\alpha_{i}}+\hat{\lambda}_{3}^{\alpha_{i}}-3+\frac{1}{\beta_{i}}\left(\left(J^{\mathrm{el}}\right)^{-\alpha_{i} \beta_{i}}-1\right)\right]
$$

where $\mu_{i}, \alpha_{i}$ and $\beta_{i}$ are the Ogden-Hill hyperfoam material constants which have to be determined from experimental stress-strain data by curve fitting. The $\beta_{i}$ is related to the Poisson ratio of the hyperelastic foam and determines the compressibility of the material. When $\beta_{i}=0$, the Poisson ratio is zero and there is no Poisson effect. $N$ is the curve fitting order [9].

\subsection{Head injury criterion}

Head injury criterion (HIC) is a biomechanical criterion, measured to assess the level of pedestrian protection. It is calculated from the head acceleration with $t_{2}-t_{1} \leq 15 \mathrm{~ms}$.

$$
H I C=\max \left[\frac{1}{t_{2}-t_{1}} \int_{t_{1}}^{t_{2}} a \mathrm{~d} t\right]^{2.5}\left(t_{2}-t_{1}\right) .
$$

In this equation, $a$ is acceleration and $t$ is time. The $t_{1}$ and $t_{2}$ time points are selected to maximize the HIC value. Biomedical limit of less than 1000 for EuroNCAP should not be exceeded during the headform tests [10].
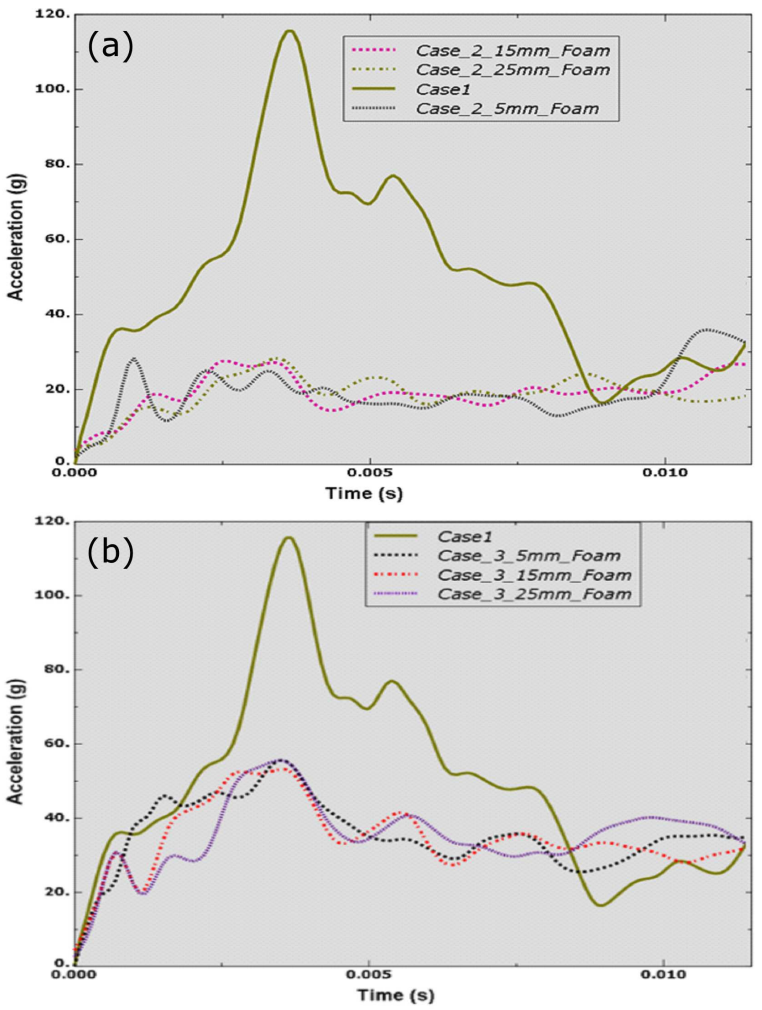

Fig. 4. Adult head - car hood FE simulations of acceleration-time curves. (a) Case 1 and case 2, (b) case 1 and case 3 . 


\section{Results and discussion}

The FE simulation results are shown in Fig. 4a and b by comparing with the original car hood results (case 1). These curves were obtained using the acceleration-time data of the the adult headform reference point during impact of the adult headform with the car hood. The HIC values were calculated using these acceleration time curves. The curve of reference car hood shows the highest peak acceleration. All calculated results are given in Table III.

TABLE III

Comparison of all cases according to results of finite element analysis $(m-$ mass, $d-$ deflection). Case 1 Original steel car hood, Case $2-0.3 \mathrm{~mm}$ aluminum face sheets sandwich hoods, Case $3-0.3 \mathrm{~mm}$ steel face sheets sandwich hoods.

\begin{tabular}{l|c|c|c|c|c|c|c}
\hline \hline & Case 1 & \multicolumn{3}{|c|}{ Case 2 } & \multicolumn{3}{c}{ Case 3 } \\
\hline foam & without & $5 \mathrm{~mm}$ & $15 \mathrm{~mm}$ & $25 \mathrm{~mm}$ & $5 \mathrm{~mm}$ & $15 \mathrm{~mm}$ & $25 \mathrm{~mm}$ \\
HIC & 454 & 378 & 368 & 345 & 367 & 333 & 291 \\
$m[\mathrm{~kg}]$ & 14.29 & 2.73 & 3.27 & 3.81 & 7.15 & 7.69 & 8.23 \\
$d[\mathrm{~mm}]$ & 113.1 & 156.7 & 149.6 & 144.8 & 132.6 & 128.2 & 122.9
\end{tabular}

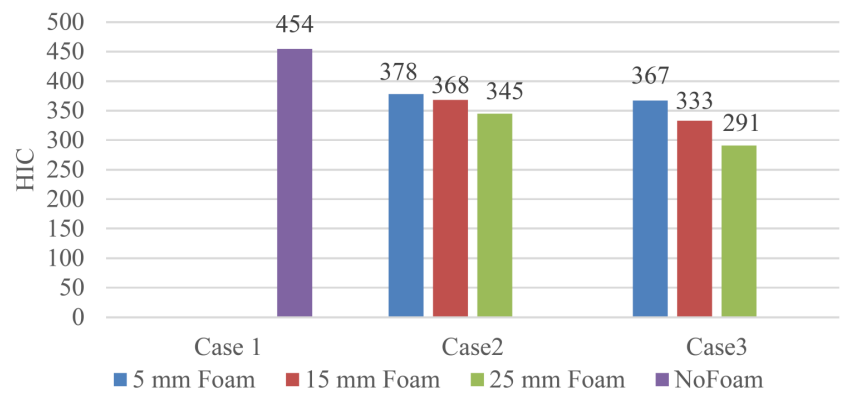

Fig. 5. Results of HIC FE simulations of adult head car hood impact.

Both the steel and the aluminum face sheet sandwich panels for each foam core thicknesses show better performance than the original steel car hood. All sandwich panels are much lighter than the reference car hood. However, the deflections of the panels are higher than that of the original panel. The HIC performance of all models is presented in Fig .5. The HIC values of the steel face sheet sandwich panels were lower than those of the aluminum face sheets sandwich panels. Although the strength of the selected steel face sheets was smaller than that of the aluminum face sheets, the elastic modulus of steel is much higher than the that of aluminum. Therefore, the steel face sheets were better dissipating the local headform impact energy over the foam surface and depth. As a result of this behavior, aluminum face sheet sandwich hoods show larger deflection than the steel sandwich panels.

\section{Conclusions}

In the presented study three types of car hoods were analyzed using FEM. In the analysis, an adult head form was impacted with the investigated car hood surfaces. In case 1 an original steel car hood, in case 2 an aluminum face sheets-PU foam core sandwich car hood and in case 3 a steel face sheets-PU foam core sandwich car hood were analyzed. Sandwich panel face sheets and core thicknesses were changed and the calculated HIC, mass, and deflection were compared with the results of the original car hood. The lowest HIC values were achieved in case 2 and case 3 . Both cases show better results than the original steel car hood, regarding the pedestrian protection. The bending rigidity of the sandwich panels affected the energy absorption performance of the sandwich panels. Using sandwich panels, the weight of the car hood can be reduced by a significant amount. That means the sandwich car hood can be used for lightweight vehicle design. Moreover, for all cases, the displacement of the car hoods was also checked for any contact with engine compartment parts.

\section{Acknowledgments}

The authors would like to thank Oyak-Renault Automotive Company for their support.

\section{References}

[1] J. Spicka, J. Vychytil, L. Hyncik, Applied and Computational Mechanics 10, 139 (2016).

[2] Q.I. Liu, Y. Xia, Q. Zhou, J.T. Wang, Proceedings of the 21st International Technical Conference on the Enhanced Safety of Vehicles (ESV), International Congress Center Stuttgart, Germany 2009, June 1518, paper nr. 09-0356.

[3] D. Valladares, J.J. Alba, I. Altubo, Adv. Mech. Eng. 9, 1 (2017).

[4] J. Hu, K.D. Klinich, Int. J. Vehicle Safety 8, 22 (2015).

[5] P. Cruz, C. Mitjans, J. Vinyals, in: ABAQUS Users' Conference Proceedings, Boston, Massachusetts, May 25-27, 2004, p. 189.

[6] ASM Aerospace Specification Metals Inc., Specifications of Aluminum 2024-T3.

[7] C. Briody, B. Duignan, S. Jerrams, in: Proceedings of the rth European Conference on Constitutive Models for Rubber (ECCMR), Dublin, Ireland, 20-23 September, 2011, p. 143.

[8] G. Liang, K. Chandrashekhara, Eng. Struct. 30, 2002 (2008).

[9] E.H. Twizell, R.W. Ogden, J. Aust. Math. Soc. Ser. B. Applied Mathematics 24, 424 (1983).

[10] C. Pinecki and R. Zeitouni, in: The 20th International Technical Conference on the Enhanced Safety of Vehicles Conference (ESV), Lyon, France, June 18-21, 2007, paper Nr. 07-0307-W. 